\title{
Standardisation in telE-learning: A critical analysis
}

\author{
Juan Santos, Manuel Caeiro, Judith Rodríguez and Luis Anido \\ Departamento de Ingeniería Telemática, Universidad de Vigo, Spain
}

\begin{abstract}
Over the last few years there has been a proliferation of many heterogeneous tele-learning systems. This outcome has been a consequence of the increased use of the internet and its technological capabilities as the supporting environment for this kind of system. This heterogeneity means that, in most cases, different systems cannot interoperate, and learning resources developed for one system cannot be reused in another. To overcome these disadvantages it is necessary to look at a standardisation process. This paper presents an upto-date critical survey of the work in the main institutions involved in this process, together with the presentation and analysis of the most outstanding outcomes.
\end{abstract}

Key words: standardisation, data models, XML, interoperability

\section{INTRODUCTION}

The increasing use of the internet and its technological capabilities allows a high number of internet-based distance learning platforms to be developed. As they are usually developed ad hoc, to meet the requirements of a particular institution, heterogeneous systems appear with no interoperability mechanism among them. Important efforts are in place in the learning technology standardisation process, lead by several institutions and projects. Their main aim is to contribute to the definition of standards on learning data and metadata, and to give recommendations for the development of software architecture devoted to web-based education.

Much work has been done and is being done in the learning technology standardisation area. Among the main contributors to this effort are the IEEE's Learning Technologies Standardization Committee (LTSC, 2001), IMS (2001), the Aviation Industry Computer-based Training Committee (AICC, 2001), the US Department of Defense's Advanced Distributed

The original version of this chapter was revised: The copyright line was incorrect. This has been corrected. The Erratum to this chapter is available at DOI: 10.1007/978-0-387-35615-0_52 
Learning (ADL) initiative (2001), the Alliance of Remote Instructional Authoring and Distribution Networks for Europe (ARIADNE) project (2001), the Getting Educational Talk Across Leading edge Technologies project (GESTALT, 2001), Promoting Multimedia access to Education and Training in European Society (PROMETEUS, 2001), European Committee for Standardisation (CEN)/Information Society Standardization Systems (ISSS)/Learning Technologies Workshop (LT, 2001), and the Gateway to Education Materials (GEM) project (2001).

The IEEE's LTSC is the institution that is actually gathering recommendations and proposals from other learning standardisation institutions and projects. Specifications that have been approved by the IEEE go through a more rigorous process to become ANSI or ISO standards. In fact, a new ISO/IEC JTC1 Standards Committee for Learning Technologies, SC36 (ISO/IEC,2001) was approved in November 1999.

\section{FIELDS OF STANDARDISATION}

There are several aspects that must be standardised since they are present in almost all learning technology systems. Some institutions involved in the standardisation process have developed architectures that contain all the components for a generic learning environment. Among them, the component responsible for delivering learning contents and tracking student progress stands out. Great efforts have been put into the standardisation of its interfaces, which define the behaviour of the learning run time. Also, in order to improve the management, location, reuse, and evaluation of learning resources and contents, these systems are working with different metadata schemes. Student management and administration is another common function. Common student data includes learners' personal information, preferences, etc. Standardisation on this aims at the reuse of student records and profiles. It is also necessary to define the format of the courses, namely, how their contents, structures, and behaviours are organised and how they can be imported/exported. This standardisation process is being developed at the time of this writing and, therefore, this survey may encourage the reader to contribute to this process from his/her own experience.

\subsection{Educational metadata}

One of the main contributors in this field has been the IEEE's LTSC with the 'Learning Object Metadata' (LOM) specification (Hodgins, 2001). The first version of LOM was delivered in 1998, and it was a co-ordinated proposal from the IMS Initiative and ARIADNE. Following this first version 
of LOM the remaining institutions joined their efforts to improve contributions to the proposal. In fact, LOM is now in its sixth version and can be considered a de facto standard within the learning community.

LOM specifies the syntax and semantics of learning object metadata, defined as the attributes required to fully and adequately describe a learning object. LOM defines a total amount of sixty attributes grouped into nine meaningful categories, which tries to reflect all aspects that must be considered in a pedagogical environment.

A complete survey on metadata and the relationship among the different proposals can be found in Anido et al. (2002).

\subsection{Educational content organisation}

One of the key aspects that makes it impossible to reuse the contents developed by one particular vendor is that they need to be delivered using the software developed by the same vendor. Even when common formats (for example, HTML) are used, the adaptation of the contents to a particular tele-learning platform must be done manually.

The AICC proposes a versatile course structure format within its document 'Guidelines for Interoperability' (Hyde, 2001). The AICC names Structure Elements as those parts of the course that will be shown to the learners. These elements can be of two different types: Assignable Units and Blocks. The first ones are used to describe the smallest elements of instruction or testing that are delivered to the learner (for example, a HTML page). The latter are groupings of Assignable Units and other Blocks.

The SCORM (Dodds, 2001) of the DoD's ADL Initiative includes a proposal for content structure format named CSF (Content Structure Format). The CSF is directly based on the AICC proposal, although it is extended to include additional characteristics. Moreover, the CSF is encoded using XML which is more suitable for web environments than the file format proposed by the AICC. Although the first version of the CSF included all elements and semantics gathered in the AICC model, after some implementation attempts, several unused elements were discarded.

\subsection{Learner assessment formats}

The proposals in this field addressed the need for defining formats for tests and questionnaires that allow not only learner assessment but the exchange of assessment material and results among different platforms.

For the moment the only proposal is the one from the IMS project in its documents 'Question and Test Interoperability Specification' (QTI, 2001) known as QTI. This specification is comprised of ten documents. 
The QTI specification, defined in XML, describes the format for the representation of question and test data together with their corresponding result reports. The specification has a powerful set of features enabling the exchange of a wide range of question types, plus a number of extension facilities to support proprietary features. However, it is structured so that it is easy to represent from simple test to complex assessment materials.

\section{$2.4 \quad$ Content packaging}

The need to exchange educational resources between tele-learning platforms and authoring tools has created the development of content packaging formats and procedures. In this way, the definition of a single entity (for example, a file) will make course transfer easier among different systems. This single entity will encapsulate educational content together with all related data (structure and associated metadata).

The IMS project is leading the standardisation process in this field. Its document 'Content Packaging Specification' (Anderson and McKell, 2001) proposes an information model that describes the data structures that must be used to exchange educational content. The key element defined in the specification is the Package. It is a single compressed file (for example, .cab, .jar, .zip) that will be interchanged between authoring tool, and between this kind of tool and the software responsible for managing and delivering the contents to students. The Package is composed of two main elements: (1) the IMS Manifest File, which is an XML file that describes the encapsulated resources and, optionally, their organisation; and (2) the Resources Collection, which is a set of physical files that store resources being described in the Manifest, such as web pages, media files, assessment objects, etc.

\subsection{Student management}

As happens in conventional educational environments, tele-learning platforms must handle information about students. Usually this information comes from three different sources: personal information (for example, name), preference data (for example, desktop appearance) and academic information (for example, grades). In addition to this information, telelearning platforms have to deal with security and privacy issues, those aspects related with students' organisation and scheduling, etc.

The first recommendation made in this field is the one from the IEEE's LTSC in its document 'Public and Private Information (PAPI)' (Farance, 2000). The PAPI specification defines the syntax and semantics for a student information model which must be used to characterise a student and his/her 
knowledge and abilities. This model is intended to be portable, implementation independent, and generally accepted.

The IMS project has made its own proposal focused on student management. The IMS has two main working lines in this field. On the one hand, the IMS Profile Initiative (Smith, Tansey and Robson, 2001) is devoted to the definition of a student profile model. On the other hand the IMS Enterprise Initiative (Collier and Veres, 1999) is working on the definition of standard structures to allow interoperability in different learning-related processes: personal profile maintenance, group management, enrolment management, and final results processing. Both initiatives are not independent and their work is highly related.

\subsection{Run time environments}

Specifications on run time environments deal with a common problem: in the past, authoring systems made the customer a captive of his own content management system or LMS (we use this acronym to refer to this kind of system as they are formally termed in the learning technology community as Learning Management Systems). Many times it was very difficult or even impossible to carry learning content created for a particular LMS to another one. In order to avoid this dependence between the LMS and contents, there must be a common way to create contents and to communicate content with the LMS through a standard data model.

The DoD's ADL initiative and the AICC are the major contributors to this field. The ADL Initiative as part of its SCORM (Dodds, 2001) has defined a run time environment based on the AICC 'CMI Guidelines for Interoperability' specification (Hyde, 2001). Therefore we will only explain the first one.

The ADL run time environment includes a specific launch protocol to initiate learning content, content to LMS application program interface (API) and a data model defining the data that is exchanged between an LMS environment and executable content at run time.

\section{STANDARDISATION PROCESS ANALYSIS}

Tele-learning standardisation is an active continuously evolving process. In fact, some of the presented proposals have existed for less than one month at the time of this writing. So far, none of them have achieved the status of an 'official' standard, although some of these specification can be considered as de facto standards among the tele-learning developers' community. Different proposals, coming from the institutions involved in this 
standardisation process, appear in parallel. Eventually, the tele-learning community try to reach a concensus around the more mature specifications.

Focusing the analysis on the work developed until now, the first conclusion is that these efforts have been centred on the definition of common formats and data models to fully describe (i.e. both syntactically and semantically) the information involved in a tele-learning environment. Particularly, information models of interest are those transferable among different, maybe heterogeneous, tele-learning platforms.

However, in order to achieve complete interoperability we also need to reach a concensus on the software architecture and interface definition that should be provided by a tele-learning system. Such concensus would allow the building of new tele-learning systems from reusable components and, at the same time, the sharing of services offered by those components, potentially developed by different vendors, in heterogenous tele-learning systems.

Let us give an example to illustrate this point: so far, the different elements that compose a tele-learning system are developed by the same vendor (for example, run time environment, student management and learner record repository, learning object repository management, etc). Interoperability at software interface level would allow, for example, the runtime environment of our institutions to make use of the services provided by an external learner record repository management component or access and use courses stored in a third-party learning object repository. For this to be possible, we must clearly identify the software interfaces to access these external modules.

Therefore, it is possible to identify two different phases in the standardisation process. The first one, standardisation of data models and formats, where mature results have been already obtained. The second one, architecture and software services standardisation, with scarce results so far.

Although this paper has presented only the results of the first phase, some proposals can be found for the second one. For example, the AICC has made a proposal of an architecture for learning platforms in its document 'Learning Technology System Architecture' (Farance and Tonkel, 2001). But, it is a high-level and conceptual architecture that identifies the processes and data flows that are involved in all learning systems. It neither defines the architecture components nor the services that must be offered by those components. The GESTALT project proposed, from a previous business model, is a concrete software architecture that identifies the components for a whole tele-learning system (GESTALT, 2001). However, this architecture is defined from the results of previous project component interfaces which were only partially published and poorly documented. 
Proposals for the run time environments (section/ref $\{$ runtime-label $\}$ ) are related to this second standardisation phase. Although these specifications are clearly defined and have proven their value in practical applications, they are restricted just to one of the multiple components that form a complete tele-learning system. We need to cover the definition of services for the rest of the modules involved following the same rigorous and strict procedure.

So far, some already standard-compliant tele-learning components are: TopClass (2001), IntraLearn (2001) or Click2Learn (2001), which are compatible with the SCORM and CMI specifications or Microsoft's LRN, 2001), compliant with IMS's QTI specification. More are expected in the near future.

\section{REFERENCES}

ADL (2001) US Department of Defense. Advanced Distributed Learning (ADL) initiative. Available at http://www.adlnet.or

AICC (2001) Aviation Industry Computer Based Training Committee. Available at http://www.aicc.org

Anderson, T. and McKell, M. (2001) IMS Content Packaging Information Model. Final Specification Version 1.1.2, IMS project.

Anido, L., Fernández, M., Caeiro, M., Santos, J., Rodríguez, J. and Llamas, M. (2002) Educational Metadata and Brokerage for Learning Resources. ACM Computers and Education, 38, (4), 351-374

ARIADNE (2001) The Alliance of Remote Instructional Authoring and Distribution Networks for Europe. Web site at http://ariadne.unil.ch

CEN/ISSS/LT (2001) European Committee for Standardisation (CEN), Information Society Standardisation Systems (ISSS), Learning Technologies Workshop (LT). Available at http://www.cenorm.be/isss/Workshop/lt/

Click2learn (2001) Click2learn - Making Knowledge a Tangible Asset. Available at http://home.click2learn.com/en/home/index.asp

Collier, G. and Veres, W. (1999) IMS Enterprise Information Model. Final Specification Version 1.01, IMS project.

Dodds, P. (2001) Sharable Content Object Reference Model (SCORM). The SCORM Aggregation Model. Technical Report Version 1.2, ADL Initiative.

Farance, F. (2000) IEEE P1484.2/D7. Draft Standard for Learning Technology. Public and Private Information (PAPI) for Learners (PAPI Learner). Working Draft 7, IEEE's LTSC.

Farance, F. and Tonkel, J. (2001) IEEE P1484.1/D9-pre. Draft Standard for Learning Technology. Learning Technology System Architecture (LTSA). Draft Standard Version 9, IEEE.

GEM (2001) Gateway to Educational Materials. Available at http://www.geminfo.org

GESTALT (2001) Getting Educational System Talk Across Leading edge Technologies project. Available at http://www.fdgroup.co.uk/gestalt

Hodgins, W. (2001) Draft Standard for Learning Object Metadata (LOM). Technical Report 6.0, IEEE's LTSC.

Hyde, J. (2001) CMI Guidelines for Interoperability. Technical Report Revision 3.5 release, AICC. 
IMS (2001) IMS Global Learning Consortium. Available at http://www.imsproject.org

IntraLearn (2001) IntraLearn Software Corporation: e-Learning platforms. Web site at http://www.intralearn.com

ISO/IEC (2001) International Standardisation Organization/Institute Electrotechnical Commission Sub-Committee for Learning Technologies (ISO/IEC JTC1 SC36). Available at http://www.jtc1sc36.org

LTSC (2001) Learning Technologies Standardisation Committee. Available at http://ltsc.ieee.org

Microsoft (2001) Learning Resource iNterchange (LRN) Toolkit. Available at http://www.microsoft.com/elearn/

PROMETEUS (2001) PROmoting Multimedia access to Education and Training in EUropean Society. Available at http://prometeus.org

QTI (2001). IMS Question and Test Interoperability: An Overview. Public Draft Version 1.2, IMS project. Available at http://www.imsproject.org/question/ index.html

Smythe, C., Tansey, F. and Robson, R. (2001) IMS Learner Information Package. Information Model Specification. Final Specification Version 1.0, IMS project.

TopClass (2001) WBT System - Powering the e-Learning Revolution. Available at http://www.wbtsystems.com

\section{BIOGRAPHIES}

Juan Santos is a telecommunication engineer (1998). He has been involved in several projects related to distance learning and e-commerce. He is assistant professor at the University of Vigo. Manuel Caeiro received a telecommunication engineering degree (1999) from the University of Vigo. Currently, he teaches computer architecture and software engineering at the Telecommunication School where he is working towards his Ph.D. Judith Rodríguez received her telecommunication engineering degree (1999) from the University of Vigo. In addition to teaching, her main interests are in educational metadata and information retrieval. Luis Anido received a telecommunication engineering (1997) and doctorate in telecommunications (2001) degrees from the University of Vigo. His main interests are in distance learning and of object-oriented distributed systems

\section{ACKNOWLEDGEMENTS}

We want to thank 'Xunta de Galicia' and 'Ministerio de Ciencia y Tecnología' for their partial support for this work under grants 'Arquitecturas distribuidas para Teleservicios' (PGIDT00TIC32203PR) and 'CORBALearn: Interfaz de Dominio guiada por Estándares para Aprendizaje Electrónico' (TIC2001-3767) respectively. 